\title{
Genetic Diversity of Nigella sativa from Different Geographies Using RAPD Markers
}

\author{
Sudhir S. P. ${ }^{1, ~ *, ~ A l a g a p p a n ~ K u m a r a p p a n ~}{ }^{2}$, Jainendra Malakar ${ }^{3}$, H. N. Verma ${ }^{1}$ \\ ${ }^{1}$ Department of Life Science, Jaipur National University, Jaipur, India \\ ${ }^{2}$ Department of Microbiology, Marine Biology, and Virology, University of Modern Sciences, Dubai, UAE \\ ${ }^{3}$ Department of Science, Kuvempu University, Shimoga, India
}

\section{Email address:}

spsjaipurnationaluniversity@gmail.com (Sudhir S. P.)

${ }^{*}$ Corresponding author

\section{To cite this article:}

Sudhir S. P., Alagappan Kumarappan, Jainendra Malakar, H. N. Verma. Genetic Diversity of Nigella sativa from Different Geographies Using RAPD Markers. American Journal of Life Sciences. Vol. 4, No. 6, 2016, pp. 175-180. doi: 10.11648/j.ajls.20160406.15

Received: October 8, 2016; Accepted: November 10, 2016; Published: December 12, 2016

\begin{abstract}
Nigella sativa is one of the important commercial medicinal herbs. It is extensively used in the Middle East and the Indian subcontinent. It is used in various medicinal, food and cosmetic preparations. It is proved to be anti-diabetic, antiallergic, anti-cancer, antibacterial, antioxidant (free radical scavenger), anti-inflammatory, and immunomodulatory agent. The medicinal value of Nigella sativa seed is linked to its rich chemical contents, which is significantly influenced by geographical location, environmental conditions, and genetic makeup. In this study, the genetic diversity of Nigella sativa plant using RAPD markers was investigated. The samples were collected from various geographies like India, Pakistan, Saudi Arabia, Egypt, Oman, Syria, Tunisia, and Turkey. Plant DNA was extracted using Norgen's Plant/Fungi DNA Isolation Kit. 20 different Random amplified polymorphic DNA (RAPD) primers were used to study the polymorphism in amplified bands among the 8 DNA samples of Nigella sativa from different geographies. Out of 20 RAPD primer used, 8 RAPD primers had provided amplification during PCR and scorable bands on $1.5 \%$ agarose gel electrophoresis. Common DNA bands or fragments present in all accessions were not included in data as they are of a non-informative type. Only unambiguous and scorable polymorphic fragments were taken into consideration for analysis. The polymorphic bands were scored as 1 (as present) and 0 (as absent). Using UPGMA (unweighted pair group method with arithmetic averages) and similarity coefficients, the relationships among the accessions were established. Based on the UPGMA method, the dendrogram divided the eight accessions into 4 clusters. Cluster 1 consisted of accessions S1 (India) and S2 (Pakistan) with a minute diversity of 0.101 . Cluster 2 consisted of accessions S4 (Saudi Arabia), S6 (Syria) and S8 (Tunisia) along with S7 (Turkey) accession with minute genetic deviation. Cluster 3 consisted of accession S3 (Egypt). Cluster 4 consisted of accession S5 (Oman). Accession S3 (Egypt) and S5 (Oman) shown high genetic variations from other accession under study. The dendrogram indicated that there is significant impact of geographies on genetic diversity of Nigella sativa accession tested. This genetic diversity enables the Nigella sativa to adapt itself to varied environmental conditions in these geographies. The information on genetic diversity can further be linked to active medicinal compounds of the Nigella sativa seed. This could be very useful for the selection of germplasm resource for breeding and commercial sourcing.
\end{abstract}

Keywords: Nigella Sativa, Kalongi, Genetic Diversity, Random Amplified Polymorphic DNA (RAPD) Markers

\section{Introduction}

Nigella sativa seed is widely used medicinal herb. It is one of the popular spices in the Middle East and Asia and Eastern Europe. It is known as Black Seed, Love-in-a-mist, Fennel Flower Black cumin, Roman Coriander, Nutmeg flower, a
Barakah Shooneez, Habb al-barka, Habba Sauda, Krishana Jiraka, Upakunchika and Kalonji. Nigella sativa is an annual flowering plant and belongs to family Ranunculaceae (buttercup family). Nigella sativa is a native to South and Southwest Asia but also domesticated in Europe.

Prophet Mohammed has mentioned Black seed as the seed 
of blessings, which can cure all the ailments except death [1]. This message had triggered much research in medicinal property of black seed. It is proven to be an anti-diabetic, anti-allergic, anti-cancer, antibacterial, antioxidant (free radical scavenger), anti-inflammatory. It acts as an immunomodulatory agent, improves a respiratory, gastrointestinal, immune, and nervous system [2]. As there is no mention of any plant species by Prophet Mohammed as black seed plant, Nigella sativa seed had been considered as cited seed looking at significant therapeutic utility. Nigella sativa seed is now one of the extensively studied herbal medicinal material and reported to have antimicrobial, antioxidant, anti-aging, hair growth promoter, sun protection, anti-cancer activity, Immunomodulatory, Cardiovascular, anti-oxytocic, wound healing and anti-inflammatory activity [3, 4]. Nigella sativa is used in its raw and other forms like seed oil, seed paste and extracts. The various researchers studied the comparative chemical composition of extracts and oils obtained from Nigella sativa from different geographies and reported wide variation [5,6]. As Nigella sativa seed has tremendous commercial value and hence it is proven for commercial adulteration and substitution [7]. In few geographies, it is mistaken with morphologically similar but biologically different seeds [8]. Looking at different sourcing points of Nigella sativa seeds it is necessary to standardize the source, basis its composition of active compounds. This study brings the significant information about the genetic diversity of Nigella sativa, which further can be linked with its chemical composition to standardize the source of Nigella sativa.

Recently there are many research studies which tried to understand the genetic diversity and its linkages with the yield of produce, adaptation to diverse environmental conditions, breeding and conservation strategies. There are various genetic markers are being used to study genetic diversity and linkages to various aspects like ISSR (Inter-simple sequence repeats (ISSRs) ) marker with morphological study used to estimate the genetic variation in 117 Trachyspermum ammi accessions belonging to 25 populations collected from different geographical regions in Iran [9], Capsicum (Pepper ) is quite important agriculture product in China. Genetic diversity in Capsicum spp. germplasm from China was studied using simple sequence repeat (SSR). Results of the study indicated that genetic diversity in Capsicum spp. were structured by migration of genotypes followed by human selection for cultivar types in agreement with consumption modes and adaptation to the highly diversified agroclimatic conditions [10]. Genetic diversity in 30 Ginkgo biloba half-sib families was analyzed using an AFLP (amplified fragment length polymorphism) marker, this study led to a strategy for the selection of improved varieties of Ginko biloba half-sib families and the zoning of the improved varieties on a national scale [11]. Paeonia jishanensis is an endangered ornamental and medicinal plant from China. Genetic diversity and population structure of this plant was studied using 21 EST-SSR markers in China. The study indicated limited gene flow hindered by geographical, physical barriers and its breeding system (facultative vegetative reproduction). This is a significant observation for the conservation and utilization of this endangered species [12]. Ulmus lamellose is an endangered and primarily distributed in North China was studied for its genetic diversity. 16 natural populations of Ulmus lamellosa was evaluated by morphological traits and sequence-related amplified polymorphism (SRAP) markers. Molecular and morphological markers indicate that Ulums lamellosa has high genetic diversity from different region, and this is probably due to the biological characteristics, distribution and modes of reproduction [13]. In a study genetic diversity among the 32 accession of Nigella sativa from various region of Pakistan was studied using 58 primers. 15 primers generated $66 \%$ polymorphic bands, revealing a high level of polymorphism among these genotypes. Further UPGMA cluster analysis divided the 32 accessions into 7 distinct clusters, indicating genetic diversity amongst this accession. The grouping pattern of clusters was related well with principal component analysis [22]. Although there are studies which focus on genetic diversity of Nigella sativa in specific countries or region are available, the study focusing on genetic diversity among the Nigella sativa from different countries are not reported till date. Present study targets at determining the genetic diversity amongst 8 Nigella sativa genotypes using RAPD markers and establishing the genetic relationships amongst these genotypes. This knowledge of variations in genetic makeup and their relationship among different genotypes would prove quite useful for selection of germplasm resource for breeding and commercial sourcing.

\section{Material and Methods}

a) Plant material

Total eight samples of Nigella sativa from geographies like India, Pakistan, Saudi Arabia, Syria, Turkey, Oman, Tunisia, and Egypt were used for study. All samples are labeled with their details and kept in Herbarium of Department of Life Science, Jaipur National University, and Jaipur.

Table 1. Details of Samples.

\begin{tabular}{ll}
\hline Description of Samples & Identification of Sample \\
\hline Nigella sativa Seeds - India & JNUJ/SPS/NS/S1 \\
Nigella sativa Seeds - Pakistan & JNUJ/SPS/NS/S2 \\
Nigella sativa Seeds - Egypt & JNUJ/SPS/NS/S3 \\
Nigella sativa Seeds - Saudi Arabia & JNUJ/SPS/NS/S4 \\
Nigella sativa Seeds - Oman & JNUJ/SPS/NS/S5 \\
Nigella sativa Seeds - Syria & JNUJ/SPS/NS/S6 \\
Nigella sativa Seeds - Turkey & JNUJ/SPS/NS/S7 \\
Nigella sativa Seeds - Tunisia & JNUJ/SPS/NS/S8 \\
\hline
\end{tabular}

Samples were collected from eight countries which are major producer of this herb. 


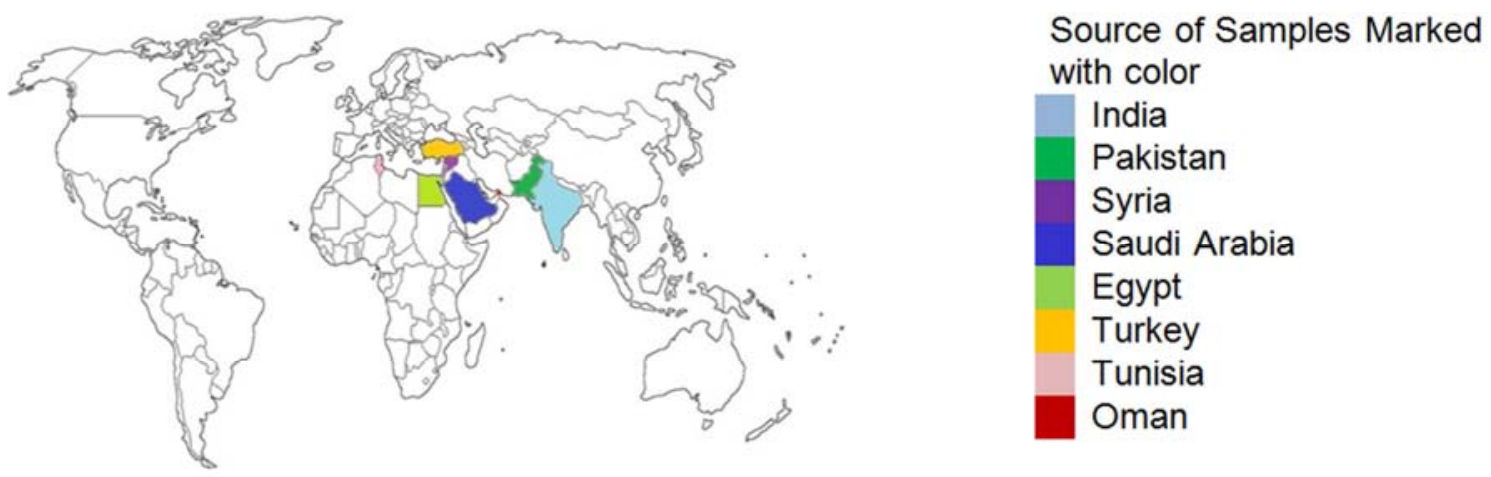

Figure 1. Locations of samples collected.

\section{b) DNA extraction}

Plant DNA was separated from Seed coat cells using plant/fungi DNA isolation kit from Norgen Biotek, Canada (DNA Isolation Kit Product \# 26200) [14] following manufacturer's protocol. Purified DNA was preserved at $-20^{\circ}$ $\mathrm{C}$ till further use. Further, extracted DNA was examined using $0.8 \%$ gel electrophoresis stained with ethidium bromide.

c) RAPD Primer and PCR procedure

20 RAPD primers (decamer oligonucleotides of arbitrary sequence) were used for PCR amplification.

Table 2. Details of Primer (Decamer) used and their properties.

\begin{tabular}{llll}
\hline S.No. & Primers & 'Sequence (5' to 3') & PCR response \\
\hline 1 & OPS01 & 5'-CTACTGCGCT-3' & - \\
2 & OPS02 & 5'-CCTCTGACTG-3' & - \\
3 & OPS03 & 5'-CAGAGGTCCC-3' & + \\
4 & OPS04 & 5'-CACCCCCTTG-3' & + \\
5 & OPS05 & 5'-TTTGGGGCCT-3' & + \\
6 & OPS06 & 5'-GATACCTCGG-3' & - \\
7 & OPS07 & 5'-TCCGATGCTG-3' & - \\
8 & OPZ10 & 5'-CCGACAAACC-3' & - \\
9 & OPA05 & 5'-AGGGGTCTTG-3' & - \\
10 & OPA07 & 5'-GAAACGGGTG-3' & - \\
11 & OPA18 & 5'-AGGTGACCGT-3' & - \\
12 & OPAG13 & 5'-GGCTTGGCGA-3' & + \\
13 & OPE04 & 5'-GTGACATGCC-3' & + \\
14 & OPE18 & 5'-GGACTGCAGA-3' & + \\
15 & OPF01 & 5'-ACGGATCCTG-3' & + \\
16 & OPF10 & 5'-GGAAGCTTGG-3' & + \\
17 & OPN03 & 5'-GGTACTCCCC-3' & - \\
18 & OPN04 & 5'-GACCGACCCA-3' & - \\
19 & OPN05 & 5'-ACTGAACGCC-3' & - \\
20 & OPN06 & 5'-GAGACGCACA-3' & - \\
\hline & & &
\end{tabular}

(+ indicates amplification - indicates no amplification or low response)

\subsection{Optimization of RAPD Protocol}

PCR technology is quite sensitive to variations in experimental parameters like $\mathrm{pH}$ values, template DNA Concentration, effects of magnesium and length of the denaturation. Applied Biosystems, USA) Model 2720 were used to carry out DNA amplification. Total 20 primers were initially screened against eight samples of DNA extracted from Nigella sativa seed. Annealing temperature was optimized for running reactions at various temperatures. Out of 20 RAPD primers eight primers provided amplifications, and they were further selected for experimentation. Programming of PCR thermocycler was done basis optimization, denaturation step one cycle $\left(94^{\circ} \mathrm{C}\right.$ for $\left.3 \mathrm{~min}\right)$, 35 cycles $\left(94^{\circ} \mathrm{C}\right.$ for $1 \mathrm{~min}, 55^{\circ} \mathrm{C}$ for $1 \mathrm{~min}, 72^{\circ} \mathrm{C}$ for $\left.1 \mathrm{~min}\right)$ and one cycle $72^{\circ} \mathrm{C}$ for $7 \mathrm{~min}$ and then held at $4{ }^{\circ} \mathrm{C}$ until the tubes were removed.

\subsection{PCR Reaction}

Selected RAPD primers (Table 2) were used to perform PCR reaction with plant DNA extracted from seed coat cell of Nigella sativa from different geographies. PCR was performed using a reaction mixture of a total volume of $20 \mu \mathrm{l}$ and contained $10 \mu \mathrm{l}$ of Taq PCR Master Mix (Norgen Biotek, Canada), $7 \mu \mathrm{l}$ distilled water, $2 \mu \mathrm{l}$ primer $(20 \mu \mathrm{M})$ and $1 \mu \mathrm{l}$ of the DNA template $(50-80 \mathrm{ng} / \mu \mathrm{l})$. The PCR conditions maintained were as follows, one cycle $\left(94^{\circ} \mathrm{C}\right.$ for $\left.3 \mathrm{~min}\right), 35$ cycles $\left(94^{\circ} \mathrm{C}\right.$ for $1 \mathrm{~min}, 36^{\circ} \mathrm{C}$ for $1 \mathrm{~min}, 72^{\circ} \mathrm{C}$ for $2 \mathrm{~min}$ ) and one cycle $72^{\circ} \mathrm{C}$ for $10 \mathrm{~min}$. Amplified PCR products were checked on $1.5 \%$ agarose gel electrophoresis for different bands patterns, and the results were used for further analysis

\subsection{Gel Electrophoresis}

All visible and unambiguously scorable bands or fragments were studied. The bands present in one sample and absent in the other samples were considered as polymorphic bands. These Polymorphic bands or fragments were used to investigate the linkage with the trait. RAPD bands were separated electrophoretically on $1.5 \%$ agarose gels, stained with ethidium bromide, and photographed on a UV transilluminator using a digital camera.

\subsection{Data Analysis}

RAPDs are dominant markers [15]. Hence they can be scored simple scoring system like present-absent. Ethidium bromide stained polyacrylamide gels were photographed and used to score the data for RAPD analysis. Individual DNA band or fragment amplified was treated as a unit character. Such RAPD fragments were scored as 1 for present or 0 for absent for each of the primer-accession combinations. 
Presence or absence of specific fragment indicates the representation of that particular sequence in the amplified plant DNA samples. In this case presence or absence of particular band or fragment basis their mobility is more important than their intensity. The presence and absence of the bands was scored in a binary data matrix. Common DNA bands or fragments present in all accessions were not included in data as they are of non-informative type.

Table 3. Details of amplified fragments and polymorphic fragments.

\begin{tabular}{|c|c|c|c|c|}
\hline Primers & Sequence (5' to 3') & $\begin{array}{l}\text { Total Number of amplified } \\
\text { Bands/Fragments }\end{array}$ & $\begin{array}{l}\text { Number of polymorphic } \\
\text { Bands/Fragments }\end{array}$ & \% Polymorphic loci \\
\hline OPS03 & 5'-CAGAGGTCCC-3' & 16 & 14 & $87.5 \%$ \\
\hline OPS04 & 5'-CACCCCCTTG-3' & 16 & 11 & $68.75 \%$ \\
\hline OPS05 & 5’-TTTGGGGCCT-3’' & 16 & 9 & $56.25 \%$ \\
\hline OPAG13 & 5'-GGCTTGGCGA-3' & 16 & 14 & $87.5 \%$ \\
\hline OPE04 & 5'-GTGACATGCC-3' & 16 & 11 & 68.75 \\
\hline OPE18 & 5'-GGACTGCAGA-3' & 18 & 11 & $61.11 \%$ \\
\hline OPF01 & 5'-ACGGATCCTG-3' & 24 & 19 & $79.16 \%$ \\
\hline OPF10 & 5'-GGAAGCTTGG-3' & 16 & 9 & $56.25 \%$ \\
\hline
\end{tabular}

Total 138 bands were observed, out of which 86 were designated as polymorphic bands, which is of $71 \%$ band observed. Highest number of amplified bands was observed in OPF01 primer, followed by OPE18 and OPS03, OPS04, OPS05, OPAG13, OPE04, OPF10. Average number of amplified bands per primer observed were 17 in number.

Further UPGMA software (http://genomes.urv.es/UPGMA/) was used to draw dendrogram. Similarity Matrix was prepared with Jaccard Coefficient.

Table 4. Similarity Matrix computed with Jaccard coefficient.

\begin{tabular}{lllllllll}
\hline & S1 & S2 & S3 & S4 & S5 & S6 & S7 & S8 \\
\hline S1 & 1 & 0.769 & 0.154 & 0.533 & 0.5 & 0.533 & 0.4 & 0.533 \\
S2 & & 1 & 0.385 & 0.733 & 0.4 & 0.733 & 0.6 & 0.733 \\
S3 & & & 1 & 0.385 & 0 & 0.385 & 0.455 & 0.385 \\
S4 & & & & 1 & 0.615 & 1 & 0.846 & 1 \\
S5 & & & & & 1 & 0.615 & 0.462 & 0.615 \\
S6 & & & & & & & 0.846 & 1 \\
S7 & & & & & & & & 1 \\
S8 & & & & & & & 0.846 \\
\hline
\end{tabular}

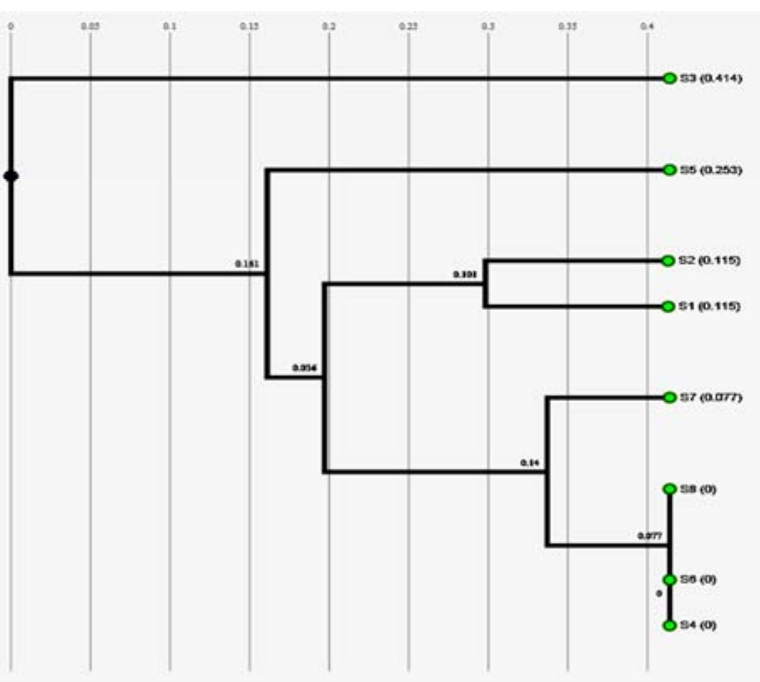

Figure 2. Dendrogram in Newick Format.

A similarity matrix based on the proportion of shared RAPD fragments was used to establish the level of relatedness among the accessions of Nigella sativa from different geographies. The pairwise Jaccard's coefficients for the genetic similarities among the 8 Nigella sativa accessions are presented in Table 4. In case of S8 (Tunisia), S6 (Syria) and S4 (Saudi Arabia) Nigella sativa accession, there is very high similarity index of 1 , while S7 (Turkey) has similarity index of 0.846 when compared with S8 (Tunisia), S6 (Syria) and S4 (Saudi Arabia). Similarity indices of S3 (Egypt) is quite low and range from 0.154 to 0.455 , this makes accession S3 (Egypt) quite different from other accession. Similarity Index for S5 (Oman) with other accessions are as little as 0 to 0.615 . Accession S1 (India) and S2 (Pakistan) found to be very close in term of genetic diversity and having similarity index of 1 and 0.769 .

Genetic similarity was calculated from the Jaccard similarity index value from RAPD Bands for all the 8 accessions of Nigella sativa for RAPD. These values were used to construct a dendrogram using Unweighted Pair Group Method with Arithmetic averages (UPGMA). Eight accessions of Nigella sativa were found to be grouped into 4 clusters. Basis the UPGMA method, the dendrogram divided the eight accessions into 4 clusters. Cluster 1 includes accession S1 (India) and S2 (Pakistan) with a minute diversity of 0.069 . Cluster 2 includes accession S4 (Saudi Arabia), S6 (Syria), S8 (Tunisia) with 0.077 genetic diversity and accession S7 (Turkey) with genetic diversity of 0.064 . Accession S3 (Egypt) and S5 (Oman) seems to have high genetic variations with the genetic diversity of 0.18 . The dendrogram indicated that there is a significant genetic variation and grouping among the Nigella sativa from different geographies. 


\section{Results}

The current study indicated the genetic variation and relatedness among the eight Nigella sativa germplasm from different geographies. The use of RAPD (Random amplified polymorphic DNA) markers in genetic diversity analysis supported the grouping of various genotypes. Basis the UPGMA method, the dendrogram divided the eight accessions from different geographies into 4 clusters. Nigella sativa accession from India and Pakistan found to be very close from genetic diversity point of view. While Nigella sativa accession from Egypt and Oman are far different from accessions from India, Pakistan, Saudi Arabia, Syria and Tunisia in terms of genetic diversity.

\section{Discussion and Conclusion}

Genetic diversity plays quite an important role in the continuity of a species as it offers the necessary adaptation to the prevailing biotic and abiotic environmental conditions [16], and enables change in the genetic composition to cope with variations in the environment. The absence of genetic diversity makes plants or crops extremely susceptible to widespread disease. Genetic diversity study is of prime important in conservation of endangered species and utilization of appropriate plant resources from diverse germplasm. RAPD is quite an important marker for genetic diversity. Recently genetic diversity in plant was studied using RAPD in quite many endangered plant species like Glehnia littoralis [16], Ulmus lamellose [13], where researchers found the factor responsible for their endangered status. In most cases, researchers found that there is good amount of genetic diversity which makes species fit to survive but over consumption of particular plant species found to the reason of endangered status.

Genetic diversity also helps in active management strategies and crop improvement program like genetic diversity study of Zingiber officinale Rosc [17] which showed that ginger undergoes genetic variation under full range of ecological conditions. In case of genetic diversity study by RAPD markers of Triticum aestivum $L$ (wheat bread) [18] varieties originating from Mediterranean region (Egypt and Greece) has shown a quite notable genetic diversion related to geographical divergence. 14 Withania accessions showed morphological and chemical constituent variation in line with genetic diversity with RAPD (Rapid Amplification of Polymorphic DNA) markers [19]. Estimation of levels of genetic diversity and structure among twelve East African Tall (EAT) coconut (Cocos nucifera L.) accessions were studied using RAPD marker. Study showed that RAPD marker could discriminate between the different provenances and provide evidence of the different origins for the coconut palms in the northern and southern parts of coastal coconut-growing belt. The two major clusters concur well with the history and distribution of coconuts in the coastal belt of Tanzania [20].

RAPD method can distinguish taxa and hence quite useful identification and botanical quality analysis of plant material [21]. Molecular markers like RAPD act as a complementary tool to morphological, histological, biochemical and ecological information about plants, their species and varieties. RAPD Molecular markers support the use of genetic diversity through the descriptive information they provide on the structure of gene pools and accessions [22].

In the present study, RAPD markers were used to determine genetic diversity in Nigella sativa amongst the germplasms from different geographies and their genetic relationships. It was concluded that RAPD technique was a useful tool in identifying Nigella sativa germplasm and determining genetic relationships among the accession from different geographies. Genetic diversity is quite important for any plant or crop to adapt different environmental and ecological conditions in various geographic.

Although RAPD markers meet all requirements of important molecular markers, it has few serious drawbacks like it is the dominant nature of markers, pattern of non-reproducibility nature, and difficulty in establishing homology of amplification products with similar molecular weights. These drawbacks sometimes decrease the quality of information obtained [23]. In practical RAPD method is still in use extensively mainly due to the cost, speed and efficiency of the technique to generate large numbers of markers in a short period compared with other methods.

\section{References}

[1] Al-Bukhari. MI. Division (71) on medicine. In Sahi AlBukhari, the collection of authentic sayings of Prophet Mohammad (peace be upon him). 2nd ed. Hilal Yayinlari, Ankara, Turkey, 1976.

[2] Zahra Gholamnezhad, Rana Keyhanmanesh, Mohammad Hossien Boskabady, Anti-inflammatory, antioxidant, and immunomodulatory aspects of Nigella sativa for its preventive and bronchodilatory effects on obstructive respiratory diseases: A review of basic and clinical evidence, Journal of Functional Foods, Volume 17, August 2015, Pages 910-927, ISSN 1756-4646, http: //dx.doi.org/10.1016/j.jff.2015.06.032. (http://www.sciencedirect.com/science/article/pii/S175646461 5003266).

[3] Padmaa, M. and Paarakh (2010). Nigella sativa.Linn.A comprehensive review. Indian Journal of Natural Products and Resources 1(4): 409-429.

[4] Dermatological effects of Nigella sativa, Salih H. M. Aljabrea, Omar M. Alakloby a, Mohammad A. Randhaw, Journal of Dermatology \& Dermatologic Surgery 19 (2015) 92-98.

[5] Ghanya N. Al-Naqeep, Maznah M. Ismail, Adel S. Al-Zubairi and Norhaizan M. Esa, 2009. Nutrients Composition and Minerals Content of Three Different Samples of Nigella sativa L. Cultivated in Yemen. Asian Journal of Biological Sciences, 2: 43-48. DOI: 10.3923/ajbs.2009.43.48, http://scialert.net/abstract/?doi=ajbs.2009.43.48. 
[6] Mohamed Ezzat Abd El-Hack, Mahmoud Alagawany, Mayada Ragab Farag, Ruchi Tiwari, Kumaragurubaran Karthik and Kuldeep Dhama, 2016. Nutritional, Healthical and Therapeutic Efficacy of Black Cumin (Nigella sativa) in Animals, Poultry and Humans. International Journal of Pharmacology, 12: 232-248.

[7] Handbook of herbs and spices, Volume 2,2004, Edited by,K. V. Peter,CRC Press Boca Raton Boston New York Washington, DC. Page 225-226.

[8] Rania Mubarak AwadObaid, Anti-Mycetoma, anti-oxidant and Phytochemical Screening of Nigella sativa seeds, A thesis for Master Degree in pharmacy (pharmacognosy), The National Ribat University Faculty of Graduate studies \& Scientific Research, May 2015.

[9] Elham Fadaei Heidari, Mehdi Rahimmalek, Shahram Mohammadi, Mohammad Hossein Ehtemam, Genetic structure and diversity of ajowan (Trachyspermum ammi) populations based on molecular, morphological markers, and volatile oil content, Industrial Crops and Products, Volume 92, 15 December 2016, Pages 186-196, ISSN 0926-6690, http://dx.doi.org/10.1016/j.indcrop.2016.08.014.

(http://www.sciencedirect.com/science/article/pii/S092666901 6305271).

[10] Xiao-min ZHANG, Zheng-hai ZHANG, Xiao-zhen GU, Sheng-li MAO, Xi-xiang LI, Joël Chadœuf, Alain Palloix, Lihao WANG, Bao-xi ZHANG, Genetic diversity of pepper (Capsicum spp.) germplasm resources in China reflects selection for cultivar types and spatial distribution, Journal of Integrative Agriculture, Volume 15, Issue 9, September 2016, Pages 1991-2001, ISSN 2095-3119, http://dx.doi.org/10.1016/S2095-3119(16)61364-3.

(http://www.sciencedirect.com/science/article/pii/S209531191 6613643).

[11] Haixia Tang, Shiyan Xing, Jihong Li, Xuan Wang, Limin Sun, Shuhui Du, Xiaojing Liu, Genetic diversity of Ginkgo biloba halfsib families based on AFLP technology, Biochemical Systematics and Ecology, Volume 68, October 2016, Pages 58-65, ISSN 03051978, http://dx.doi.org/10.1016/j.bse.2016.06.009.

(http://www.sciencedirect.com/science/article/pii/S030519781630 1533).

[12] Xing-Xing Xu, Fang-Yun Cheng, Hong-Li Xian, Li-Ping Peng, Genetic diversity and population structure of endangered endemic Paeonia jishanensis in China and conservation implications, Biochemical Systematics and Ecology, Volume 66, June 2016, Pages 319-325, ISSN 0305-1978, http://dx.doi.org/10.1016/j.bse.2016.05.003. (http://www.sciencedirect.com/science/article/pii/S030519781630 1016).

[13] Li Liu, Wei Chen, Xin Zheng, Jing Li, Dong-Ting Yan, Lin Liu, Xin Liu, Yi-Ling Wang, Genetic diversity of Ulmus lamellosa by morphological traits and sequence-related amplified polymorphism (SRAP) markers, Biochemical Systematics and Ecology, Volume 66, June 2016, Pages 272280, ISSN 0305-1978,

http://dx.doi.org/10.1016/j.bse.2016.04.017. (http://www.sciencedirect.com/science/article/pii/S030519781 6300965).Norgen's Plant/Fungi DNA Isolation Kit Product Insert Product \# 26200.
[14] N. Senthil Kumar1 and G. Gurusubramanian, Random amplified polymorphic DNA (RAPD) markers and its applications,Proceedings of the "National Level Workshop on Random Amplified Polymorphic DNA (RAPD) Markers and It's Applications"organized on 20-21 May 2011 by the Departments of Biotechnology \& Zoology, Bioinformatics Infrastructure Facility \& State Biotech Hub, Mizoram University.

[15] Ailan Wang, Ping Zhang, Xiao Liu, Jianguang Liang, Weiwei $\mathrm{Li}$, Genetic structure and diversity of Glehnia littoralis, an endangered medicinal plant in China, Biochemical Systematics and Ecology, Volume 66, June 2016, Pages 265271, ISSN 0305-1978, http://dx.doi.org/10.1016/j.bse.2016.04.019.

(http://www.sciencedirect.com/science/article/pii/S030519781 6300989).

[16] Kamran Ashraf, Altaf Ahmad, Anis Chaudhary, Mohd. Mujeeb, Sayeed Ahmad, Mohd. Amir, N. Mallick, Genetic diversity analysis of Zingiber Officinale Roscoe by RAPD collected from subcontinent of India, Saudi Journal of Biological Sciences, Volume 21, Issue 2, April 2014, Pages 159-165, ISSN 1319-562X http://dx.doi.org/10.1016/j.sjbs.2013.09.005.(http://www.scien cedirect.com/science/article/pii/S1319562X1300082X).

[17] Kamal Fouad Abdellatif, Hanaa Mahdy AbouZeid, Assessment of genetic diversity of Mediterranean bread wheat using Randomly Amplified Polymorphic DNA (RAPD) markers, Journal of Genetic Engineering and Biotechnology, Volume 9, Issue 2, December 2011, Pages 157-163, ISSN 1687-157X,

http://dx.doi.org/10.1016/j.jgeb.2011.10.002.(http://www.scien cedirect.com/science/article/pii/S1687157X11000321).

[18] Punit Kumar Khanna, Ratna Chandra, Arun Kumar, Nidhi Dogra, Heena Gupta, Gourav Gupta, Vijeshwar Verma. Correlation between morphological, chemical and RAPD markers for assessing genetic diversity in Withania somnifera (L.) Dunal, J. Crop Sci. Biotechnol. (2014) 17: 27. doi:10.1007/s12892-013-0104-8.

[19] Linus I. Masumbuko, Salama Sinje, Alois Kullaya, Genetic Diversity and Structure of East African Tall Coconuts in Tanzania Using RAPD Markers, Open Journal of Genetics, 2014, 4, 175-181, Published Online April 2014 in SciRes. http://www.scirp.org/journal/ojgen,http://dx.doi.org/10.4236/o jgen.2014.42018.

[20] Kapteyn J, Simon JE (2002) Th e use of RAPDs for assessment of identity, diversity and quality of Echinacea. In. Trends in new crops and new uses. (Eds. J Janick, A Whipkey), ASHS Press, Alexandria, VA. pp. 509-513.

[21] IQBAL, Muhammad Sajjad, Shahid NADEEM, Shahid MEHBOOB, and Abdul GHAFOOR. Exploration of Genotype Specific Fingerprinting of Nigella Sativa L. Using RAPD Markers. TUBITAK, 2011. doi:10.3906/tar-1001-622.

[22] Korzun V, Malyshev S, Voylokov AV, Borner A (2001) A genetic map of rye (Scale cereale L.) combining RFLP, isozyme, microsatellite and gene loci. Th eor Appl Genet 102: 709-717. doi:10.1007/s001220051701. 